ing areas, and erectile angiomatous tumors situated under the skin or on the mucous membrane.

We all know what a puzzle these varieties of vascular tumors have been in the past from a therapeutic point of view. Electrolysis, caustics, $\mathrm{x}$-rays, knife and $\mathrm{CO}_{2}$ snow have been our chief weapons in the past, but radium offers us to-day a means, and perhaps the best means, of ridding the patient of these disfiguring birthmarks.

The "cross-fire" method of application finds its most accurate and useful employment in the treatment of angiomata. By combining it with weak or medium filtering it considerably increases the intensity of the most deeply penetrating (surpénétrant) rays, whilst allowing some action to those of medium penetration.

\section{Pigmentary Naevi.}

The pigmented moles and birthmarks offer rather an unfavorable target for radium. There is no specific influence exerted in this tissue, that is, there is no selective action, and to accomplish results one must produce inflammatory reactions. But even by this method, which we have learned is fortunately unnecessary in vascular new growths, we may accomplish often striking results. On the other hand, it is best not to treat by radium, hairless, slightly café au lait, superficial patches. The resulting chalk-white scars and the frequently resulting telangiectases produce a disfigurement greater than the original lesion.

\section{Hairy Naevi.}

Radium has a distinct action on the pilo-sebaceous glands, and depilation is not a difficult process by this means. The cosmetic result is good, and we have not to fear the ugly and numerous small scars which follow the destruction of hairs by the x-rays.

\section{Tuberculosis Cutis.}

The various forms of tuberculosis of the skin may be treated by radium, but the rays have no selective action on tuberculous tissues, and to accomplish results one must employ the emanations as a destructive agent. This treatment requires powerful action, both wide and deep, and long-continued and careful supervision of the resulting scars. Tuberculosis of the mucous membranes can, however, be improved without any perceptible reaction. As to the permanent value of the results in the treatment of tuberculosis, they are inferior in every way to those obtained in carcinoma, angioma and keloid.

\section{Miscellaneous Diseases.}

In the course of our work we have been led to try the therapeutic power of radium on various recalcitrant diseases, and it is interesting to record varying favorable results in obstinate cases of psoriasis, angiokeratoma, linear ichthyosis, several forms of dyskeratosis and hyperkeratosis, lichen planus, acne rosacea, rhinophyma and certain types of papilloma. We do not wish to consider radium as the first therapeutic choice in all these various diseases, but simply ask you to bear in mind that, when other and more arcessible means have failed to produce cure or alleviation, that as a last resort radium may accomplish the desired curative results.

\section{ANALGESIC WFFECIS OF RADIUM.}

There can be no doubt of the power of radium to relieve congestion, and this ability and the alterative qualities of the emanations have proved of great service in relieving the pains of certain epitheliomata and carcinomata and of numerous keloids. We are able to record also relief in many cases of neuralgia, including that accompanying and that following herpes zoster, neuritis, gonorrheal and rheumatic arthropathies and iritis, and other experimenters have gained frequent favorable results in the deeper-seated pains of gastritis, tabes dorsalis and sciatica.

Such favorable experiences led us to try the effects of radium in the pruritic discases of the skin, and as a result we have met with decided success in the relief of pruritus ani, with and without accompanving hemorrhoids, pruritus vulva, neuro-dermatitis, lichenification and chronic eczema. We have accomplished these results by the use of rays of weak and medium penetration which seem to have a selective action on pruritus and produce their favorable results without concomitant inflammatory reaction.

Our method of procedure in the treatment of such necessarily large surfaces, as occur in chronic eczema of the arm, for instance, is to apply the radium in the form of a varnish spread on linen. Our technic in combating these disturbances of nervous origin is to employ large apparatus with powerful radio-activity; to make short exposures with intervals between them; to use weak and medium rays in as large numbers as possible; and to avoid superadded inflammation.

[Note. - A large part of the evening was devoted to the exhibition of lantern slides illustrating graphically the truth of Dr. Wickham's spoken words, and the audience seemed much impressed by the modesty and sineerity of the speaker. - C. J. WHitw.]

\section{THE CARE AND MANAGEMENT OF THE}

\section{TABBETIC BIAADDIR. II. FIIOLOGY.}

$$
\text { BY J. MBLLINGEK HARNEY, M.D., BOSTUN, MABH., }
$$

Assistant Surgeon to the (ienito-Urinary Out-Patient Department, Massachusetts Generul IIospital. (From the Genito-Lirimary Out-Patient 1)epartment, Maswachusets
General Hospitul.)

IN a previous paper (Boston Medical AND Surgical Journal, Dec. 22, 1910) the writer discussed the signs and symptoms of tabes dorsalis. I will now attempt to explain their causation.

At the outset I would say that this is a matter of some difficulty. This is owing to the fact that not only is the anatomy of the urinary mechanism, especially the sphineter apparatus, still in more or less dispute, but the nervous control of the bladder functions is even more a matter of controversy. Such a state of affairs exists in spite 
of innumerable researches, both clinical and experimental.

The muscular structure of the bladder proper is clearly described. It consists of three coats of unstriated muscle: an outer, whose fibers are chiefly longitudinal in direction; a middle, the direction of whose fibers is mainly circular or transverse; and an inner, arranged more or less longitudinally like the outer coat, but with many of the muscle bundles obliquely disposed. The latter is usually incomplete, being found only on the inferior wall, and to some extent on the superior wall. It is not found on the base of the bladder. No sharp line of demarcation exists between the different layers. This is especially true at the neck of the bladder, where all the coats are more or less intermingled. The so-called " detrusor urina" is generally considered to consist of the longitudinal fibers, with or without the circular fibers. Thus, broadly speaking, when we say " detrusor," we refer to the bladder muscles as a whole.

Many writers deny the existence of a true internal sphineter of the bladder. Without going into a discussion of the merits of the arguments, I will say at once that, according to the best of evidence, such a sphincter does exist. Further, all are agreed on the presence of an external striated sphineter. The bladder outlet is, therefore, guarded by two sphincters, an inner of smooth muscle, and an outer of striated muscle. The latter is often reforred to as the urethral sphincter, or by the familiar names of "cut-off muscle" or " constrictor urethra," as it divides the membranous from the bulbous urethra.

For an account of these sphincters I shall draw freely from the recent description given by Albarran and Noguès. The smooth musclo fibers of the anterior urethra, scattered throughout its length, join in forming a more or less complete ring at the peno-scrotal angle. This, however, plays no part in urination. These fibers extend upwards in two layers, an inner longitudinal and an outer circular, to surround the membranous and prostatic urethra (Fig. 1, 9 and 10). At the neck of the bladder there is the internal sphincter of smooth muscle, formed by a continuation of the fibers already described into those of the inner (Fig. 1, 14) and middle coats (Fig. 1, 15) of the detrusor muscle. It is the middle (circular) layer of the latter, thickened at the bladder neck, and continuous with the outer circular coat of smooth muscle fibers surrounding the urethra, which is called the internal or smooth sphincter (Fig. 1,8). It is the tonicity of this sphincter which prevents involuntary evacuation of urine.

Around the membranous urethra there is found a powerful external sphineter of striated muscle, which prolongs itself upwards like a horseshoe with the opening posterior, along the whole anterior aspect of the prostatic urethra, external to the prostrate itself, up to the bladder (Fig. 1, 7; Fig. 2, $A, B, C, D, 3$ ). When the prostatic urethra and the neck of the bladder are removed, as in total perineal prostatectomy, incontinence does not occur. This is due solely to the presence of the striated sphincter surrounding the membranous urethra.

In the female, the anatomy of the external sphincter is identical with that of the male, except for the interposition of the prostate in the latter. Owing to this, and to the presence of the vagina, the striated external sphincter of the fomale completely surrounds the urethra at the bladder neck, while below it is open behind. Its relation to the urethra is thus reversed in the fomale.

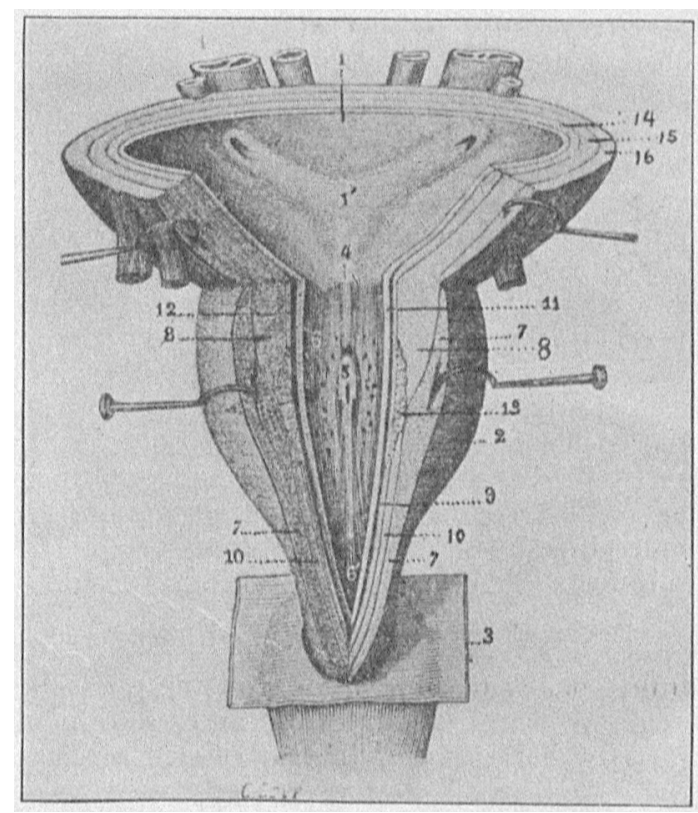

Fıo. 1.7 Jonkitudinal section showing, 1,1', Bladder and trigone. 2, 13, P'rostake. 3. 'T'riangular ligament (inferior layer). 4 , Neck of hlindder. 5 , Verumontanum. 6 , 6 , Prostutic and membranous urcthrio. 7, External strinted sphincter. 8, In ternal smooth sphincter. 9, Jongitudinal smooth fibers of urethre. 10, Circular smooth fibers of urethra. 11, Urethra mucosn. 12, Vascular coat. 14, Internal muscle cont of bladder. 15 Middle musele cont of bladder. 16, Outer muselo coat of
bladder.

The accompanying illustrations, photographed from those in 'Testut's "Traite d'Anatomio" Humaine," show the anatomy of this region very well. Fig. 1, with its explanatory legend, will make clear the appearance of the two sphincters in longitudinal section. It also shows the relation of these sphincters to the three layers of the detrusor muscle. For the appearances of the two sphincters in cross-section the reader is referred to Fig. 2 and its appended description.

It was stated above that the tonicity of the internal sphincter alone provented involuntary micturition. As evidence of this, Albarran and Nogues recall the fact that when the prostatic urethra is divided, incontinence does not occur, although striated muscle is not found in this location. The tonicity of this sphincter has also been amply demonstrated by the experiments of Courtade and Guyon. They found that even without any nervous excitation the 
internal sphincter will resist a pressure of 12 or $15 \mathrm{~cm}$., occasionally $20 \mathrm{~cm}$., of water.

On the other hand, the resistance of the external sphincter has been shown by these investigators to equal a pressure of from 70 to $100 \mathrm{~cm}$. or more of water. It is thus seen that the presence of two distinct sphincters has been well demonstrated on both anatomical and physiological grounds, and it has also been shown that each sphincter offers its own special resistance to pressure.

In considering the nerve supply of the bladder and sphincters, we find ourselves at once in a hewildering maze of theory and fact. According to Courtade and Guyon, the nerves of the bladder, including the internal sphincter, come from the hypogastric plexus, situated in the loose connective tissue on both sides of the middle part of the rectum. This plexus receives its fibers from two sources, - from the sacral nerves (usually the third and fourth), and from the inferior mesenteric ganglion. The branches from the sacral nerves running to the plexus are two or three in number and are known as the nervi erigentes. They run straight to the plexus without passing through the sympathetic chain. There is also evidence (Guyon, Albarran and Testut) that in the course of these nerves, and even in the detrusor muscle itself, there are numerous ganglia. Their presence is not as yet fully demonstrated, and their action is far from clear. The external sphincter is supplied not only by branches from the hypogastric plexus, but also by a branch from the internal pudic nerve.

The vesical spinal center is said to be on a level with the third and fourth sacral segments of the spinal cord (Frankl-Hochwart), although it is fair to say that its precise location is still in doubt. Another center is found in the medulla. Also, according to Frankl-Hochwart, there is evidence to show that in the brain there is a center in the motor arca of the cortex, and a subcortical center in the striate body, and probably also in the optic thalamus. Impulses for urination are believed to travel along the lateral pyramidal tracts.

To quote Albarran and Noguc̀s, " All organic functions are the result of a reflex, and micturition offers no exception to the rule. In every reflex three things are necessary, - sensory nerves, a center and a motor nerve. The sensory nerves transmit the excitation to the center, which transmits it in its turn to the motor nerve."

As regards the action of these nerves and the particular part supposed to be supplied by each, I will give briefly the results of the experiments of Guyon. The latter, working with Courtade in 1895, showed conclusively that the sacral nerves act only on the longitudinal fibers of the bladder, while the hypogastric nerves act only on the circular fibers. As the longitudinal fibers are the ones chiefly concerned in the evacuation of the bladder, they concluded that the act of urination depended almost exclusively on the nerves coming from the medulla by the intervention of the sacral plexus. Further experiment in 1900 led Guyon to conclude that the nervi erigentes were at the same time the sensory and motor nerves of micturition.

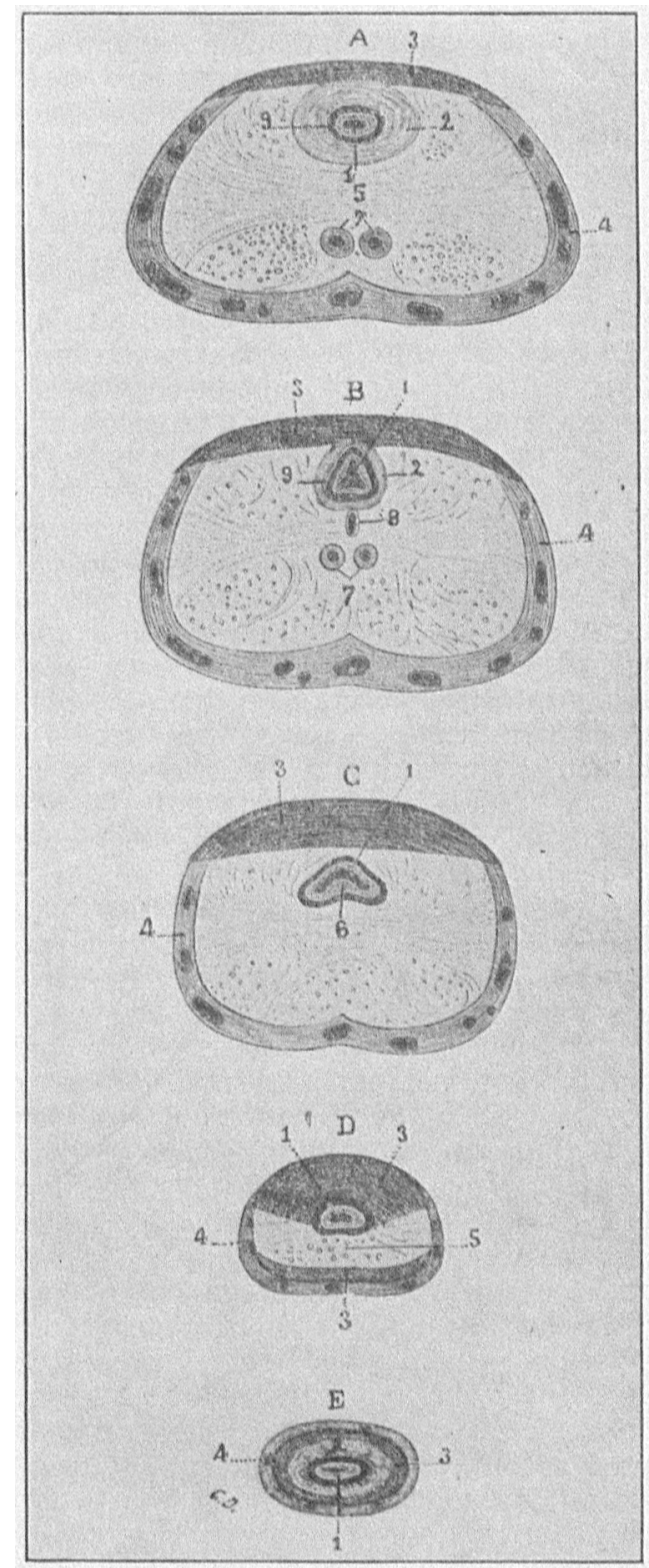

Fia. II. The external urethral sphineter seen in cross sections of the prostute. $A .6 \mathrm{~mm}$. below the bladder neck. $B .15 \mathrm{~mm}$. bolow tho bladder neck. C. $20 \mathrm{~mm}$. below the bladdor neck. $D$. At the npex of the prostate. $E$. Behind the membranous urethra. 1, lumen of urethra. 2 , Internal smooth sphineter. 3 portion of prostute. 0 , Verumontanum. 7 , Ejoculatory ducts. 8 . Uterus mesculinus. 9, Vascular layer of urethrn.

Guyon showed, in 1901, that, after section of the nervi crigentes and injection of an irritant (silver nitrate) into the bladder, the latter would still contract and expel a part of its contents. From this he concluded that the tonicity of the bladder muscles was in certain conditions independent of all medullary and even of all extra- 
vesical nervous influence. This is also the opinion of Hirt, Orth, Kocher, Bernheim, Ehrlich and Brieger, Von Zeissl, Henle, Goltz, Bernstein, Dubois and Landois.

The foregoing description of the anatomy, nerve supply and physiology of the urinary mechanism enables us to take up now the consideration of normal micturition. Again referring to Guyon, the theory evolved by him in 1887, with certain minor modifications, seems to be almost unanimously accepted. It is briefly this:

1. Accumulation of urine in the bladder. "The tonicity is very feeble, the extensibility great and the contractility small " (Albarran and Noguès). Intravesical pressure is nil.

2. Slow rise of intravesical pressure to 15 or $20 \mathrm{~cm}$. of water, which we saw was the limit of resistance of the internal sphincter. Meantime the urine is retained in the bladder solely by the tonicity of this sphincter.

3. Rhythmic contractions of the detrusor muscle, each of from forty to sixty seconds' duration (Sherrington), have been going on meantime, increasing in force with the increase of pressure. The resistance of the internal sphincter is overcome and a little urine trickles through it into the posterior urethra.

4. Afferent impulses from the bladder to the lumbo-sacral cord. The desire to urinate is felt, for it has been shown that this desire depends on the irritation of the posterior urethra by the urine.

5. A reflex discharge of impulses by tho nerves of the hypogastric plexus (nervi erigentes), resulting in a rise of intravesical pressure to 70 or $100 \mathrm{ccm}$. of water, and a contraction of the whole bladder wall.

6. The external sphincter yields to this pressure, opens, and urine is forced out by the detrusor contractions, aided perhaps by those of the abdominal muscles.

At this point volition may be called forth, for it is an accepted fact that, up to a certain point, the external sphincter can be contracted so as to check urination, at least temporarily. Lack of this voluntary control of the external sphincter is seen in young infants whose bladders empty themselves as soon as the intravesical pressure overcomes the resistance of the internal sphincter. As development proceeds, volition comes into play, and the child is incontinent only at night. linally when voluntary control of the external sphincter is fully established, the desire to urinate is under practically complete mastery, as in the adult, and urination can then be started or stopped at will. It is the result of an automatic natural reflex acquired by education.

Howell states that Mosso and Pellacani have shown that the bladder is very sensitive to reflex stimuli. Psychic and sensory stimulation may cause contraction or increased tone of the organ. It is thus subject to constant change in size from reflex stimulation, and the intravesical pressure will then depend not only on the quantity of urine, but also on the tonicity of the detrusor itself. At a certain pressure stimulation of the sensory nerves occurs, and under normal conditions urination ensues. This will explain how, in conditions of emotional excitement, there may occur a strong desire to urinate with only a little fluid in the bladder.

It was seen in my first article that in tabes wo have certain signs and symptoms referable to the bladder. The signs are trabeculation, residual urine and anesthesia of the bladder neck. The symptoms are difficult urination, incontinence, dysuria, urgency, frequency, retention and absence of the desire to urinate. These must all be explained, and the explanation must find its basis, in the description already given of the anatomy and physiology of the urinary mechanism.

$I$, therefore, offer the following explanation of these signs and symptoms. It is largely a theory built up from the evidence at hand. Were there any definite statements of the condition of the nerves controlling the urinary function in tabes, this theory might be placed on a sure pathological basis. So far as I know, the nerves supplying the bladder have never been studied in tabetics. Painful micturition and irritability of the bladder neck (seen in certain cases) I consider to be a hyperesthesia, analogous to that seen in diseases of the peripheral nerves in other parts of the body.

Frunkl-Hochwart, Bierhoff and Böhme think that the urinary disorders seen in spinal cord disease are a question of true, tonic spasm of the external sphincter, and inability of this sphincter to relax, a weakness of detrusor contraction, or possibly of all three factors.

We can eliminate at once an impairment of detrusor contraction, for it has been shown by many able observers that the activity of the detrusor muscle is a pure reflex, independent of all medullary and extravesical nervous influence. If this reflex contractility does not occur, how, then, can we account for the trabeculation, which is found before any symptom or other sign of bladder disturbance, and which we also saw was, primarily at least, a result of increased work on its part? Now the cause of this extra effort is an obstacle to the stream of urine offered by the failure of the external sphincter to open. Normally when the urine is forced against this sphincter, by the contractions of the detrusor muscle, the latter, together with the presence of urine in the posterior urethra, cause a discharge of reflex impulses and the external sphincter opens. In the tabetic this sensation is dulled or absent, as shown not only by the failure of the external sphincter to open, but also by two other factors. One is the complete lack of sensibility of the posterior urethra which enables the cystoscope to be passed without the least sensation on the part of the patient, even without cocainization. The other is the lack of normal desire to urinate, so frequently seen in tabetics. Some patients lack this sensation to such an extent that they empty their bladders only once or twice in the twentyfour hours, and then more from a sense of duty than of necessity. 
When, however, the patient does urinate, the striated sphineter cannot be fully relaxed because of an increased tonicity, or because of paralysis. These factors are difficult to determine becauso this sphineter is believed to have two kinds of motility, reflex contractibility and voluntary relaxability (Hirt). The brain docs not receive in due time the sensation from the bladder. Meantime the climax of the detrusor contractions has been reached, and the tabetic empties his bladder on the downward wave of these contractions (Rehfisch, experimental). Thus the stream is slow and small. As this condition becomes more marked, the patient begins more and more to exert pressure on the bladder by the contraction of the abdominal muscles, thus aiding the action of the detrusor.

But before even the patient has any hint of it, the same difficulty of micturition has been going on in a mild form. 'The detrusor has been working against an unyielding sphincter and as a result of this extra effort trabeculas are formed. At first the detrusor can compensate for this obstruction, and, by hypertrophy and hard work, empty the bladder completely. In the course of time this compensation fails, even as heart compensation fails, and we find residual urine. We saw that some patients said they did not feel as if they emptied their bladders. This, then, accounts for this sensation.

To proceed with our theory, nocturnal incontinence occurs from a lack of sensory stimuli from bladder to brain. 'The bladder fills, contractions occur, the external sphincter is either forced by unusually violent contractions of the detrusor or is reflexly relaxed by them. During the day incontinence occurs less often, or not at all, because with the faculties alert the patient either perceives the desire to urinate and thus contracts his external sphincter voluntarily, or its reflex contraction is unconsciously increased.

Incontinenee in tabetics is usually the overflow from a full bladder. It is generally spoken of as ischuria paradoxa. The bladder reaches a certain degree of pressure; this is sufficient to force the external sphincter by the violent detrusor contractions. A little urine escapes, thus lowering the intravesical pressure. Leakage then ceases, until, by the further accumulation of urine, the intravesical pressure is again raised to a point where the external sphincter is once more forced or rclaxed and the incontinence recurs.

In somewhat the same way the momentary incontinence occurring with coughing, sneczing or any sudden muscular effort may be explained. The bladder is full, detrusor contractions are going on, the diaphragm becomes fixed, the abdominal muscles contract and compress the bladder. Aided by this pressure the detrusor is able to force a little urine through the external sphincter. This momentarily lowers the intravesical pressure, the brief contraction of the abdominal muscles ceases and leakage stops.

Finally, we must not forget the important factor of incoördination. This occurs in the muscles of locomotion; why not, therefore, in those of urination? It will aid us greatly in explaining wholly or in part the intricate puzzle before us. As Hirt says, "The necessary gradation of dosage of innervation for normal effect is destroyed." The sphincter does not open at the right moment, or with the poor "team work" it closes before the urine has had time to escape. Further evidence of the factor of incoördination is found in the educatability of the muscles concerned in urination, which I shall show later.

Still another factor must be considered in the explanation of these symptoms, namely, urinary infection. It was seen that this occurred, with a concomitant cystitis, in over $50 \%$ of cases. We also know that such an infection will cause irritability of the bladder and urgent urination in any individual. Therefore, when the symptoms of bladder infection are superimposed on those caused by the nerve and cord lesions in tabes, wo find a doubly complex picture. It may help to explain certain symptoms on the one hand, but per contra, it makes the explanation of other symptoms more difficult.

In conclusion, I wish to call attention to the " exhaustion theory" of Edinger, as set forth by Adami and Nicholls. The reparative processes in the specific cells are impaired as a result of some toxin circulating in the system. The neurones which are normally most active, or are most constantly at work, are those which suffer. These are the sensory nerves from the muscles which play an important rôle in the regulation of muscular contraction, and are constantly submitting those stimuli by which we become aware of the condition of our muscular system. The purely sensory nerves which are constantly submitting sensations from the mucous membranes would be likely to suffer and give rise to sensory disturbance. In this way the bladder disturbances may be explained as the result of a destruction of sensory impulses, which that organ is constantly transmitting.

Briefly summarizing the above remarks it can be said that,

1. The bladder is guarded by two sphineters, an internal of smooth fibers, and an external of striated fibers, of which each has its special power of resistance.

2. The function of urination is controlled by branches from the hypogastric plexus (nervi erigentes)

3. The detrusor muscle may contract reflexly without connection with the central nervous system.

4. The urinary disorders of tabes are dependent on, (a) a disturbance in the transmission of sensory impulses from bladder, (b) incoördination of the muscles of micturition, (c) urinary infection.

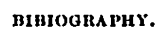

Adami and Nicholls: Principles of pathology, 1909, ii. Albarran: Quoted by Testut.

Albarran and Noguds: Assoc. Internat. d'Urol., 1008, Bernheim: Quoted by Hirt.

Bernstein: Quoted by Hirt.

Bierhoff: Quoted by Bihhune.

Böhme: Munch. Med. Wochenschr., No. 50, 1908, ii.

Brieger: Seo Ehrlich and Brieger.

Courtado and Guyon: Soc. do Biol., 1805. Ibid., 1901. 
Dubois: Quoted by Ilirt.

lidingor: Quoted by Adrini and Nicholls,

Wdingor: Quoted by Adami nnd Nicholl

Frnnkl-Hochwart: Assoc. Internnt. d'Urol., 1908, i.

Trnnkl-Hochwart: Asso

Guyon: Soc. de Biol., 1900. Seo also Courtude and Guyon.

Guyon: Soc. de Biol.j,

Hirt: Centralbl. fur die Krankheiten der IIarn- und Sex.-Org., 1902,

xiii.

Howell: Text-Book of Physiology, 1010.

Kocher: Quoted by Hirt.

landois: Quoted by Hirt.

Mosso and Pollacani: Quoted by

Nicholls: Seo Adami and Nicholls.

Noguds: Seo Albarran and Noguds.

Orth: Quoted by Hirt.

Pellacani: Sco Mosso and Pellacani.

Rehfisch: Quoted by Hirt.

errington: Schllfer's 'Text-13ook of Physiology, 1100(), ii.

Toutut: Trait6 d'Anatomic Humaine, 3. ed., Paris, 1806.

v. Zeissl: Quoted by Hirt.

\section{A BIOGRAPHY OF CIIARIIES SPON, M.D.*}

BY CHA KLIS GREENE: CUMBTON, M.D., BOBTON,

Member of the Medical Historical Society of France, etc.

Charles Spon, the son of Mathieu Spon, and Judith Bernard, his wife, was born at Lyons on Dec. 25, 1609. Little is known as to his early education, neither of his life up to 1620 , at which time he was sent to his uncle, Charles Spon, at Ulm. His biographers declare that he was particularly fond of Latin poetry, so that his professors already foresaw in him the ingenious author of the "Myologia heroica carmine expressa." His familiarity with the French language, as well as the intellectual midst in which he passed his childhood, undoubtedly contributed to give him his great facility in the study of Latin. However this may be, he preserved during his entire life his great aptitude for this dead language.

He did not remain for any length of time at Ulm, and in 1625 he was in Paris as the disciple of the philosopher, Rodon, whom he left in $\mathbf{1 6 2 7}$ to study physics in the Collège de Lizieux. In this institution, which was under the direction of the celebrated Guillaume Mazure, physies and natural sciences were taught under the name of physics. Taking all things into consideration, the preliminary studies in Spon's time were practically the same as they are to-day in the European universities, namely, the study of Latin and letters, philosophy and the natural sciences, only after which could one matriculate in the Faculty of Medicine.

Spon remained at Paris until 1632. He was fortunate enough to study under a coterie of eminent masters. He became especially intimate with Cousinot, who, at that time, had emitted his opinion on the two great medications of the period, namely, diet and bleeding, in the two following works: Non ergo phlebotamia die critico crisin imminentem remoratur, Paris, in 4, 1623, and Ergo dieta plenior securior, Paris, in 4, 1624. This friendship was of benefit to him inasmuch as when, later on, Cousinot became the first physician to Louis XIV, he obtained letters patent for his former student as quarterly physician to the king. Among other noted men who taught at Paris at this time may be mentioned Pyart, Merlet, Perreau and Charpentier.

* As Guy Patin's letters have long been consulted by both historians and physicians, it was thought that a biography of one of his most oonstant correspondants, Charles Spon, might be of interest, as little
hus been published about him. C. G. C.
In 1632 Spon went to Montpellier, where he became on intimate terms with Courtaud, the future adversary of Guy Patin, and with him he admitted the theories of Harvey. After a few months he took the bonnet of doctor and returned to Lyons, but he did not immediately commence to practice there.

His sojourns in Paris and Montpellier revealed to him the rivalry which then existed between the two Faculties, as well as between the theories taught and those who upheld them. This rivalry continued up to the end of the last eentury and contributed not a little to a wise reserve and a prudent skepticism on the part of the physicians of Lyons. 'The majority of them, like Spon, had studied at Paris, but, for some unknown reason, most of the degrees were taken at Montpellier, a fact that is made evident when one consults the works published at this time, because one moets, under the name of the author, D.M.M., more frequently than D.M.P.

Although Lyons, at this time, had no university, it possessed, on the other hand, a College of Physicians, whose reputation dated back many years, and although somewhat of a digression, a few words relative to this institution do not seem out of place, and what is to follow regarding it is quoted from Brossette's work entitled, "Nouvel Eloge de la ville de Lyon," which was published in 1711.

"The college of medicine of lyons is illustrious, not alone because of its antiquity, but also on account of several learned physicians who have belonged to it, among which, without speaking of Abascantus, praised by Galen and Andromacus, one may mention during the latter centuries Gui de Chauliac, Simon de Renodis or of Pavia, Francois Rabelais, Henri Corneille Agrippa, Michel Nostradamus, Joseph Duchesne, known under the name of Quercetan Jacques Daléchamp, Charles and Jacob Spon and several others."

"Physicians who wished to enter this college must give proof of their capacity by public examination, which is carried out with much exactness and severity, so that it frequently happens that certain candidates are refused, although they may have obtained the degree of M.D. from some university. The physicians of Lyons take the title of professor, because they give public lectures on anatomy, surgery and pharmacy: We have several excellent works on medicine as well as on other subjects composed by the physicians of Lyons belonging to the college."

In point of fact, the College of Physicians is not as ancient as Brossette would lead one to believe, its foundation, in all probability, only dating back to 1540 . In 1576 this institution was chartered by Henry III, while its statutes were confirmed in 1577. In order to become a member, it was not alone enough to pass the examinations, but the candidate must have shown that he had practiced for two years in some village in the neighborhood of Lyons. Spon, consequently, submitted to the rule and commenced practice at Pont-de-Vesle, a small town situated about a league from Mâcon. 